\title{
ROLE OF PSYCHOSOCIAL FACTORS IN VICARIOUS TRAUMATIZATION: A COMPARATIVE STUDY
}

\author{
Nazia Mustafa ${ }^{1}$, Hina Iqbal ${ }^{2}$
}

ABSTRACT:

\section{OBJECTIVES:}

The present study aimed at investigating the role of psychosocial factors such as, gender, marital status, profession, and personal history of trauma in vicarious traumatization (VT).

\section{METHODOLOGY:}

Cross sectional study was conducted at various hospitals in Rawalpindi and Islamabad over the period of 6 months from January 2018 to June 2018. A sample of 170 healthcare professionals (doctors=39, psychiatrists $=27$, psychologists $=36$, nurses $=30$ and others $=38)($ men $=67$, women $=103)$ was taken from various hospitals in Rawalpindi and Islamabad. Data were collected by using the Secondary Traumatic Stress Scale.

\section{RESULTS:}

Results revealed significant differences have been found among various groups of healthcare professionals (doctors, psychiatrist, psychologists, nurses and others) in whom psychiatrists are the most vulnerable group for vicarious traumatization and psychologists are the least vulnerable group. Moreover, healthcare professionals who are married and have personal history of trauma are more vulnerable for vicarious traumatization as compared to those who are unmarried and without personal history of trauma. No significant gender differences have been found among health care professionals on vicarious traumatization.

\section{CONCLUSION:}

The findings of present research have emphasized that vicarious traumatization must be addressed and identified in a health setting.

KEYWORDS: Vicarious Traumatization, Healthcare Professionals, Psychosocial Factors

How to cite this article:

Mustafa N, Iqbal H. Role of Psychosocial Factors In Vicarious Traumatization: A Comparative Study. J Gandhara Med Dent Sci. 2022;9(1): 53-57

https://doi.org/10.37762/jgmds.9-1.172

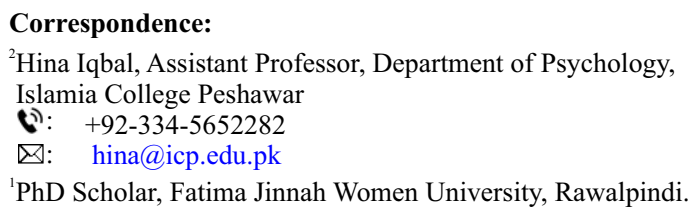

${ }^{2}$ Hina Iqbal, Assistant Professor, Department of Psychology, Islamia College Peshawar

(i): +92-334-5652282

凶: hina@icp.edu.pk

${ }^{1} \mathrm{PhD}$ Scholar, Fatima Jinnah Women University, Rawalpindi.

\section{INTRODUCTION:}

The traumatic events often have devastating impacts on health and community and along with primary victims; individuals who are involved in assisting them are also at risk of developing stress related symptoms because of the contagious nature of trauma ${ }^{1}$. This phenomenon is known as vicarious trauma and it brings changes in psychological, physical, and spiritual well-being of professionals and affects their family relations and coping strategies negatively ${ }^{2}$. These professionals include medical personnel, armed forces personnel, rescue workers, fire safety workers, mental health professionals and social workers. These all people are at risk for the growth of vicarious traumatization $^{3,4}$. Many researches have been 
conducted to see the prevalence of vicarious traumatization among individuals from different work settings. It is found that about 10 percent of these personnel get affected and $30 \%$ reported posttraumatic symptoms at high levels. A study showed high prevalence of vicarious traumatization among social workers after 20 months of terrorist attack on World Trade Centre ${ }^{5}$. Similar results were found for humanitarian aid workers in India and $8 \%$ of them met the criteria of PTSD ${ }^{6}$. Many other studies have been carried out with therapists, counselors, social workers and nurses with similar findings ${ }^{7}$. Many psychosocial factors such as gender, profession, marital status and past history of trauma play significant roles in the emergence of VT. Females are more vulnerable for trauma in general and for VT specifically ${ }^{8}$. In a research study, 56 females were studied who are wives of war veterans. Results asserted that 32 had six or more symptoms of secondary traumatic stress whereas only 3 had none of the symptoms. Twenty-two women met the diagnostic criteria for secondary traumatic stress. Furthermore, these women with VT were married longer than those without it ${ }^{9}$. According to Pearlman and Paula, trauma therapists with a personal trauma history are more vulnerable for the development of VT as they have more negative effects from the work than those without a personal history ${ }^{10}$. Though, there are many researchers conducted in various parts of the world showing the high prevalence of vicarious traumatization among all those who are working with traumatized individuals $^{11,12}$. Simultaneously, there is literature, which does not support this hypothesis that trauma affects others ${ }^{13}$. This situation creates the need to see what factors play a role in the emergence of VT. So present research is designed with the aim to see the role of psychosocial variables such as gender, marital status, profession and personal history of trauma in vicarious traumatization.

\section{METHODOLOGY:}

Present study was designed to investigate the role of psychosocial factors (gender, marital status, personal history of trauma and profession) on the occurrence of vicarious trauma among health care professionals who are working with traumatized individuals. A sample of 170 healthcare professionals $(\mathrm{men}=67$, women=103) with mean age of 31 years (range of 19 to 51 years) was taken from various private/public sector hospitals in Rawalpindi and Islamabad through purposive sampling technique. Among these professionals 39 were doctors and 27 psychiatrists, 36 were psychologists, 30 were nurses and 30 were other professionals. After obtaining their consent they were asked to fill Socio-Demographic Form and the Secondary Traumatic Stress Scale (STSS), which is designed to specifically measure secondary trauma symptoms. It is a 17-item Likert-type response format ranging from 1 (never) to 5 (very often) instrument with its reliability is 0.94 for full scale and the Intrusion, Avoidance, and Arousal subscales had alphas of $0.83,0.89$, and 0.85 , respectively ${ }^{14}$. Socio-Demographic Form is developed to measure the psychosocial factors in which participants were asked about information regarding sex, age, marital status, profession and personal history of trauma. The data was entered on SPSS-24 and analyzed. Descriptive statistics were carried out to describe the mean, SD, frequencies and reliability coefficients. Further inferential statistics involved ANOVA and t-test to compare the mean differences of various groups.

\section{RESULTS:}

Results showed that the age of participants was between the range of 19 to 51 years (Mean $=31.74$, $\mathrm{SD}=6.74)$ and Secondary Traumatic Stress Scale (STSS) $(\mathrm{r}=0.92)$ was a reliable measure for the assessment of VT.

Table 1: Means and Standard Deviations of Different Variables $(n=170)$

\begin{tabular}{|l|c|c|}
\hline \multicolumn{1}{|c|}{ Variables } & Mean & SD \\
\hline Vicarious Traumatization & 42.62 & 11.77 \\
\hline Intrusion & 11.82 & 3.28 \\
\hline Avoidance & 17.84 & 5.34 \\
\hline Arousal & 12.96 & 4.21 \\
\hline Age & 31.74 & 6.74 \\
\hline
\end{tabular}




\begin{tabular}{|c|c|c|c|c|c|c|c|c|c|}
\hline \multirow[b]{3}{*}{ Variables } & \multicolumn{2}{|c|}{ Married } & \multicolumn{2}{|c|}{ Unmarried } & \multirow[b]{3}{*}{$T$} & \multirow[b]{3}{*}{$\mathbf{p}$} & \multirow{2}{*}{\multicolumn{2}{|c|}{$95 \%$ CI }} & \multirow{3}{*}{ Cohen's d } \\
\hline & & & & & & & & & \\
\hline & Mean & SD & Mean & SD & & & $\mathbf{L L}$ & UL & \\
\hline Intrusion & 12.48 & 3.11 & 10.80 & 3.32 & 3.40 & .001 & .68 & 2.66 & .52 \\
\hline Avoidance & 19.12 & 4.96 & 15.79 & 5.34 & 4.13 & .000 & 1.73 & 4.91 & .65 \\
\hline Arousal & 14.01 & 3.90 & 11.30 & 4.18 & 4.28 & .000 & 1.46 & 3.96 & .67 \\
\hline VT & 45.60 & 10.86 & 37.89 & 11.74 & 4.36 & .000 & 4.21 & 11.20 & .72 \\
\hline
\end{tabular}

\begin{tabular}{|c|c|c|c|c|c|c|c|c|c|}
\hline \multirow[b]{3}{*}{ Variables } & \multirow{2}{*}{\multicolumn{2}{|c|}{$\begin{array}{c}\text { With PHT } \\
(n=124)\end{array}$}} & \multicolumn{2}{|c|}{ Without PHT } & \multirow[b]{3}{*}{$\mathbf{T}$} & \multirow[b]{3}{*}{$\mathbf{p}$} & & & \\
\hline & & & & & & & \multicolumn{2}{|c|}{ 95\% CI } & \multirow[t]{2}{*}{ Cohen's d } \\
\hline & Mean & SD & Mean & SD & & & LL & UL & \\
\hline Intrusion & 12.60 & 2.98 & 9.73 & 3.15 & 5.44 & .000 & 1.83 & 3.91 & .93 \\
\hline Avoidance & 19.48 & 4.70 & 13.44 & 4.36 & 7.51 & .000 & 4.45 & 7.62 & 1.33 \\
\hline Arousal & 14.02 & 3.83 & 10.11 & 3.90 & 5.84 & .000 & 2.59 & 5.23 & 1.01 \\
\hline VT & 46.11 & 10.34 & 33.29 & 10.23 & 7.14 & .000 & 9.27 & 16.37 & 1.24 \\
\hline
\end{tabular}

\begin{tabular}{|c|c|c|c|c|c|c|c|c|c|}
\hline \multirow[b]{3}{*}{ Variables } & \multicolumn{2}{|c|}{ Male } & \multicolumn{2}{|c|}{ Female } & \multirow[b]{3}{*}{$T$} & \multirow[b]{3}{*}{$\mathbf{p}$} & \multirow{2}{*}{\multicolumn{2}{|c|}{$95 \%$ CI }} & \multirow{3}{*}{ Cohen's d } \\
\hline & \multicolumn{2}{|c|}{$(n=67)$} & \multicolumn{2}{|c|}{$(n=103)$} & & & & & \\
\hline & Mean & SD & Mean & SD & & & $\mathbf{L L}$ & UL & \\
\hline Intrusion & 11.81 & 3.06 & 11.83 & 3.43 & -.037 & .970 & -1.039 & 1.000 & -.006 \\
\hline Avoidance & 18.30 & 4.73 & 18.30 & 5.70 & .912 & .363 & -.890 & 2.419 & 0 \\
\hline Arousal & 13.31 & 4.76 & 12.74 & 4.04 & .871 & .385 & -.729 & 1.880 & .12 \\
\hline VT & 43.42 & 11.15 & 42.10 & 12.18 & .714 & 476 & -2.331 & 4.972 & .11 \\
\hline & & & & & & & & & \\
\hline
\end{tabular}

\begin{tabular}{|c|c|c|c|c|c|c|c|c|c|c|c|c|c|c|c|c|}
\hline \multirow[t]{2}{*}{ Variable } & \multicolumn{2}{|c|}{$\begin{array}{c}\text { Doctors } \\
(n=39)\end{array}$} & \multicolumn{2}{|c|}{$\begin{array}{c}\text { Psychiatrists } \\
(\mathrm{n}=27)\end{array}$} & \multicolumn{2}{|c|}{$\begin{array}{c}\text { Psychologists } \\
(\mathrm{n}=36)\end{array}$} & \multicolumn{2}{|c|}{$\begin{array}{l}\text { Nurses } \\
(\mathrm{n}=30)\end{array}$} & \multicolumn{2}{|c|}{$\begin{array}{l}\text { Others } \\
(n=38)\end{array}$} & \multirow[b]{2}{*}{$\mathbf{F}$} & \multirow[b]{2}{*}{$\mathbf{i}-\mathbf{j}$} & \multirow[b]{2}{*}{$\begin{array}{c}\text { Mean D } \\
(\mathrm{i}-\mathrm{j})\end{array}$} & \multirow[b]{2}{*}{ SE } & \multicolumn{2}{|c|}{$95 \%$ CL } \\
\hline & Mean & SD & Mean & SD & Mean & SD & Mean & SD & Mean & SD & & & & & LL & UL \\
\hline VT & 43.49 & 13.14 & 49.56 & 9.73 & 36.36 & 12.37 & 41.30 & 11.60 & 43.76 & 7.83 & $5.70^{* *}$ & $\begin{array}{l}\text { Doctors- } \\
\text { Psychiatrists }\end{array}$ & $-6.07^{*}$ & 2.795 & -11.59 & -.55 \\
\hline & & & & & & & & & & & & $\begin{array}{c}\text { Doctors- } \\
\text { Psychologists } \\
\end{array}$ & $7.13^{*}$ & 2.580 & 2.03 & 12.22 \\
\hline & & & & & & & & & & & & $\begin{array}{l}\text { Psychiatrists- } \\
\text { Psychologists }\end{array}$ & $13.19^{*}$ & 2.842 & 7.58 & 18.81 \\
\hline & & & & & & & & & & & & $\begin{array}{l}\text { Psychiatrists- } \\
\text { Nurses }\end{array}$ & $8.256^{*}$ & 2.961 & 2.41 & 14.10 \\
\hline & & & & & & & & & & & & $\begin{array}{l}\text { Psychiatrists- } \\
\text { Others }\end{array}$ & $5.79^{*}$ & 2.810 & .24 & 11.34 \\
\hline & & & & & & & & & & & & $\begin{array}{l}\text { Psychologists- } \\
\text { Others }\end{array}$ & $-7.40^{*}$ & 2.596 & -12.53 & -2.28 \\
\hline
\end{tabular}

Significant level reported: between group $\mathrm{df}=4$, within group $\mathrm{df}=165$, group total $\mathrm{df}=169,{ }^{*} \mathrm{p}<.05,{ }^{* *} \mathrm{p}<.01$

\section{DISCUSSION:}

There is a series of major natural disasters such as earthquakes, floods etc. that have occurred in the world in the last few years. Unfortunately, the focus was on Asia, which suffered a $\operatorname{lot}^{15,16}$. On the other hand, most wars, insurgencies and terrorist attacks take place in Muslim world ${ }^{3}$. Pakistan is the country which faced all types of disasters. Health care professionals are individuals who help these victims. These individuals come across extreme human suffering and observe the emotions of fear, helplessness and horror on a consistent basis. This may lead to increased likelihood of experiencing a change in their own psychological functioning ${ }^{17}$. So the present study was designed to find out the role of various psychosocial factors in VT among healthcare professionals in Pakistan. During disaster situations in Pakistan, a therapist himself became a victim of psychological suffering while 
working with sufferers ${ }^{2}$. Comparison of psychosocial factors such as gender, marital status, profession and personal history of trauma were computed on the variable of VT and its components (intrusion, avoidance and arousal). Because these are important factors related to VT in previous literature. It is reported that married females are more vulnerable for $\mathrm{VT}^{9}$. A study found out that personal trauma history correlated with secondary trauma symptoms ${ }^{18}$. Results of present study show similar findings with previous literature. Results revealed significant differences have been found among various groups of healthcare professionals (doctors, psychiatrist, psychologists, nurses and others) in whom psychiatrists are the most vulnerable group for vicarious traumatization and psychologists are the least vulnerable group. Moreover, healthcare professionals who are married and have personal history of trauma are more vulnerable for vicarious traumatization as compared to those who are unmarried and without personal history of trauma. No significant gender differences have been found among health care professionals on vicarious traumatization.

\section{CONCLUSION:}

The findings of present research have emphasized that vicarious traumatization must be addressed and identified in a health setting. However, due to the relatively small sample size as well as the nonprobability convenience sampling method used, the sample is not representative of the general population. It is recommended that the present study be replicated in the future with larger and more representative samples so that the results can be generalized.

\section{CONFLICT OF INTEREST: None}

\section{FUNDING SOURCES: None}

\section{REFERENCES:}

1. Udod S, Cummings GG, Care WD, Jenkins M. Role stressors and coping strategies among nurse managers. Leadership Health Serv. 2017;30(1):29-43.

2. Mustafa N, Haleem F, Khan NS, Sardar T, Akhtar MN, Mumtaz J. Relationship of vicarious traumatization with family relations and coping strategies among healthcare professionals. Pak Armed Forces Med J. 2020;70(6):1925-8.

3. Niaz U. Women"s Mental Health in
Disaster Psychiatry. In: Christodoulou GN, Mezzich JE, Christodoulou NG, LecicTosevski D, editors. Disasters: Mental Health Context and Responses. UK: Cambridge Scholars Publishing; 2016. p. 57-68.

4. Kisner C, Colby LA, Borstad J. Therapeutic Exercise: Foundations and Techniques. $7^{\text {th }}$ ed. Philadelphia: F.A. Davis Company; 2018.

5. Cuartero ME, Campos-Vidal JF. Self-care behaviours and their relationship with satisfaction and compassion fatigue levels among social workers. Soc Work Health Care. 2019;58(3):274-90.

6. Padmanabhanunni A. The cost of caring: secondary traumatic stress and burnout among lay trauma counsellors in the Western Cape Province. S Afr J Psychol. 2020;50(3):385-94.

7. Peled-Avram M. The role of relationaloriented supervision and personal and work-related factors in the development of vicarious traumatization. Clin Soc Work J. 2017;45(1):22-32.

8. Murphy S, Elklit A, Chen YY, Ghazali SR, Shevlin M. Sex differences in PTSD symptoms: a differential item functioning approach. Psychol Trauma Theory Res Pract Policy. 2019;11(3):319.

9. Dekel R, Levinstein Y, Siegel A, Fridkin S, Svetlitzky V. Secondary traumatization of partners of war veterans: the role of boundary ambiguity. J Fam Psychol. 2016;30(1):63.

10. Cosden M, Sanford A, Koch LM, Lepore CE. Vicarious trauma and vicarious posttraumatic growth among substance abuse treatment providers. Subst Abuse. 2016;37(4):619-24.

11. Cetrano G, Tedeschi F, Rabbi L, Gosetti G, Lora A, Lamonaca D, et al. How are compassion fatigue, burnout, and compassion satisfaction affected by quality of working life? findings from a survey of mental health staff in Italy. BMC Health Serv Res. 2017;17(1):1-10.

12. Molnar BE, Meeker SA, Manners K, Tieszen L, Kalergis K, Fine JE, et al. Vicarious traumatization among child welfare and child protection professionals: a systematic review. Child Abuse Neglect. 2020;110:104679.

13. Masson F. Enhancing resilience as a selfcare strategy in professionals who are 
vicariously exposed to trauma: case study of social workers employed by the South African Police Service. J Hum Behav Soc Environ. 2019;29(1):57-75.

14. Bride BE, Robinson MR, Ye gidis B, Figly CR. The secondary traumatic stress scale. Res Soc Work Pract. 2003;13:1-16.

15. Ahmed ZS, Yousaf F, Zeb K. Socioeconomic and political determinants of terrorism in Pakistan: university students ${ }^{\text {ee }}$ perceptions. Int Stud. 2018;55(2):130-45.

16. Branson DC. Vicarious trauma, themes in research, and terminology: a review of literature. Traumatology. 2019;25(1):2.
17. Vasquez ML, Boel-Studt S. Integrating a trauma-informed care perspective in baccalaureate social work education: guiding principles. Adv Soc Work. 2017;18(1):1-24.

18. Molnar BE, Sprang G, Killian KD, Gottfried R, Emery V, Bride BE. Advancing science and practice for vicarious traumatization/secondary traumatic stress: a research agenda. Traumatology. 2017;23(2):129.

\section{CONTRIBUTORS}

1. Nazia Mustafa - Concept \& Design; Data Acquisition; Data Analysis/Interpretation; Drafting Manuscript; Critical Revision; Supervision; Final Approval

2. Hina Iqbal - Concept \& Design; Data Acquisition; Data Analysis/Interpretation; Drafting Manuscript; Critical Revision; Supervision; Final Approval

LICENSE: JGMDS publishes its articles under a Creative Commons Attribution Non-Commercial Share-Alike license (CC-BY-NC-SA 4.0) COPYRIGHTS: Authors retain the rights without any restrictions to freely download, print, share and disseminate the article for any lawful purpose. It includes scholarly networks such as Research Gate, Google Scholar, LinkedIn, Academia.edu, Twitter, and other academic or professional networking sites. 